\title{
Clinical Study of Appendicitis and Complication in Treatment in Paediatric Patients
}

\author{
Rajesh Gouri', Prakash Galani² \\ ${ }^{1}$ Associate Professor, Department of Surgery, Pacific Medical College \& Hospital, Udaipur, Rajasthan, India, ${ }^{2}$ Professor, Department of Surgery, Gujarat \\ Adani Institute of Medical Science, Bhuj, Kutch, Gujarat, India.
}

\section{Abstract}

Background: Regardless of where and with what frequency it occurs, appendicitis remains an enigma - a simple disease that, despite our best efforts, remains the most commonly misdiagnosed surgical emergency. Appendicitis continues to cause significant morbidity and still remains, although rarely, a cause of death. Hence the aim to find out among children admitted with clinical diagnosis of acute appendicitis. Subjects and Methods: This work included the study of children below 12 years of age admitted to the medical hospital with clinical diagnosis of acute appendicitis. Minimum of 200 cases over the scheduled period Methods: - Patients admitted with symptoms pertaining to the acute appendicitis were studied. Results: Maximum cases were found in the age group of 13 - 16 years. Males' prominence was found in the study. All the patients had abdominal pain, fever and vomiting were the next common clinical symptoms. Less frequent clinical symptoms were constipation and diarrhoea. Few patients had anorexia too. Conclusion: Clinical accuracy in diagnosis is $100 \%$ by comparing with the histopathological examination of all removed appendix specimens. No negative appendectomies. Postoperative complications are less frequent in children. Thorough history taking, evaluation of the clinical symptoms and signs combined with the specific tests can improve the diagnostic accuracy and significantly reduce the rate of negative appendectomy.

Keywords: Appendix, paediatric, Complications, Clinical features.

Corresponding Author: Dr. Prakash Galani, Professor, Department of Surgery, Gujarat Adani Institute of Medical Science, Bhuj, Kutch, Gujarat, India.

Received: November 2019

Accepted: December 2019

\section{Introduction}

The exact role of the appendix is not clear. It may be an area that hosts friendly bacteria, which help digestion and fight infection.It may also be related to the immune system and influence the body's ability to fight off infection. ${ }^{[1]}$

The appendix is a closed-ended, narrow, worm-like tube up to several inches in length that attaches to the cecum. The inner lining of the appendix produces a small amount of mucus that flows through the open central core of the appendix and into the cecum. The wall of the appendix contains lymphatic tissue that is part of the immune system. Like the rest of the colon, the wall of the appendix also contains a layer of muscle, but the layer of muscle is poorly developed. ${ }^{[2]}$

Appendicitis probably happens because either a stomach infection moves to the appendix or a hard piece of stool becomes trapped in the appendix, causing infection. ${ }^{[3]}$

Appendicitis can occur at any age, most commonly ranging from older children to adults in their 30s. It most commonly occurs in the second decade of life. More than 250,000appendectomies are performed in the United States each year.Due to the varying size and location of the appendix and the proximity of other organs to the appendix, it may be difficult to differentiate appendicitis from other abdominal and pelvic diseases or even during the onset of labor during pregnancy. The treatment for appendicitis usuallyis antibiotics and appendectomy. Complications of appendectomy include wound infection and abscess. ${ }^{[4,5]}$

Appendectomy for appendicitis is the most commonly performed emergency operation in the world. The establishment of a diagnosis of acute appendicitis is more difficult in young children than in the adult. ${ }^{[6]}$ The inability of young children to give an accurate history,diagnostic delays by both parents and physicians are all contributing factors.In children the physical examination findings of maximal tenderness in the right lower quadrant (RLQ) , the inability to walk or walking with a limp,pain with percussion,coughing and hopping were found to have the highest sensitivity for appendicitis. ${ }^{[7]}$

Regardless of where and with what frequency it occurs, appendicitis remains an enigma - a simple disease that, despite our best efforts, remains the most commonly misdiagnosed surgical emergency. Although the diagnosis and treatment have improved, appendicitis continues to cause significant morbidity and still remains, although rarely, a cause of death. Hence the aim to find out among children admitted with clinical diagnosis of acute appendicitis. 


\section{Subjects and Methods}

A clinical study on appendicitis in paediatric age group was conducted in the Department of Paediatric Surgery at medical hospital. This work included the study of children below 12 years of age admitted to the medical hospital with clinical diagnosis of acute appendicitis. All of them admitted as emergency. Inclusion criteria Children below $12 \mathrm{yrs}$ of age admitted to the Hospital with clinical diagnosis of acute appendicitis and willing to undergo investigations and treatment and those willing for follow up. Exclusion criteria: Children above 12 years of age. Sample size- Minimum of 200 cases over the scheduled period Methods: - Patients admitted with symptoms pertaining to the acute appendicitis were studied.

\section{Statistical Analysis}

The data was coded and entered into Microsoft Excel spreadsheet. Analysis was done using SPSS version 15 (SPSS Inc. Chicago, IL, USA) Windows software program. The variables were assessed for normality using the Kolmogorov-Smirnov test. Descriptive statistics were calculated.

\section{Result}

In this series of 200 cases, the patients who presented with acute symptoms and pre-operatively diagnosed to have acute appendicitis were studied. Maximum cases were found in the age group of $13-16$ years. Males' prominence was found in the study.

The different clinical presentations found in the patients were as follows: all the patients had abdominal pain, fever and vomiting were the next common clinical symptoms. Less frequent clinical symptoms were constipation and diarrhoea. Few patients had anorexia too.

Out of the total 200 cases that were admitted to the hospital with suspected acute appendicitis all cases were taken up for emergency surgery. Among the 200 cases that were operated all cases had acutely inflamed appendix. The percentage of inflamed appendix found on operation was 100\%. All patients diagnosed clinically as acute appendicitis were found to be accurate by confirming with the histopathologicalreports.HPE proved 100\% accuracy.

Table 1: Sex and age distribution of the child patients

\begin{tabular}{|l|l|l|l|}
\hline Age in years & Male & Female & Total \\
\hline $0-4$ & 4 & 0 & 4 \\
\hline $5-8$ & 6 & 10 & 16 \\
\hline $9-12$ & 30 & 18 & 48 \\
\hline $13-16$ & 76 & 56 & 132 \\
\hline Total & 116 & 84 & 200 \\
\hline
\end{tabular}

Table 2: clinical symptoms presentation in the paediatric patients

\begin{tabular}{|l|l|}
\hline Clinical features & Number of cases \\
\hline Anorexia & 100 \\
\hline Vomiting & 170 \\
\hline Diarrhoea & 10 \\
\hline Constipation & 8 \\
\hline Abdominal pain & 200 \\
\hline Fever & 180 \\
\hline
\end{tabular}

Discussion

Acute appendicitis remains a common abdominal emergency throughout the world. Early and accurate diagnosis of acute appendicitis is required to reduce the morbidity and mortality associated with delayed diagnosis and its complications. In addition to significant morbidity and mortality, negative appendectomy is also responsible for loss of precious staff hours and financial resources. ${ }^{[8,9]}$

The diagnosis of acute appendicitis continues to be difficult due to the variable presentation of the disease and the lack of reliable diagnostic test. Time and again, it has proved that some of the investigations already discussed are costly, time consuming; require more sophisticated equipment and expertise, while some are not feasible and not readily available. So, even today, a thorough clinical examination with basic investigations remains the cornerstone in the diagnosis of acute appendicitis. ${ }^{[10,11]}$

In the present study paediatric appendicitis is found to be more common in the 13-16yrs of age and it is found to be frequently seen in boys compared to girls.About $90 \%$ of appendicitis in our study were found to be in the 13-16 age group and about $58 \%$ of the appendicitis were found in boys. Neutrophil lymphocyte ratio(NLR) $\geq 3.5$. These results obtained in our study were comparable to the study conducted by Goodmanet al26 in which $79 \%$ of patients with appendicitis had a preoperative elevated total leukocyte count and $88 \%$ of patients had NLR $\geq 3.5$. Ultrasound abdomen showed inflamed appendix in $91 \%$ of patients which was comparable to study conducted by Hahn et al91 in which ultrasound abdomen showed an accuracy rate of $96 \%$ in diagnosing pediatric appendicitis. ${ }^{[7,12]}$

\section{Conclusion}

Ultrasound abdomen is a good predictor of paediatric appendicitis alone and in combination with the TLC and NLR increases the diagnostic value of acute appendicitis in children. It is better to perform USG in each child with acute abdominal pain, even if clinical diagnosis seems to be well established. Clinical accuracy in diagnosis is $100 \%$ by comparing with the histopathological examination of all removed appendix specimens.No negative appendectomies. Postoperative complications are less frequent in children. Thorough history taking, evaluation of the clinical symptoms and signs combined with the specific tests can improve the diagnostic accuracy and significantly reduce the rate of negative appendectomy.

\section{References}

1. Laurin M, Everett ML, Parker W: The cecal appendix: one more immune component with a function disturbed by post- industrial culture. The Anatomical Record: Advances in Integrative Anatomy and Evolutionary Biology 2011, 294:567-79.

2. COWAN DF, SMITH TL: Morphology of the lymphoid organs of the bottlenose dolphin, Tursiops truncatus. The Journal of Anatomy 1999, 194:505-17.

3. Puylaert JB: Ultrasound of Appendicitis: And Its Differential Diagnosis: Springer Science \& Business Media, 2012.

4. Wilms IM, De Hoog DE, de Visser DC, Janzing HM: Appendectomy versus antibiotic treatment for acute appendicitis. Cochrane database 
of systematic reviews 2011 .

5. Silen W, Cope Z: Cope's early diagnosis of the acute abdomen: Oxford University Press, USA, 2005.

6. Coursey CA, Nelson RC, Patel MB, Cochran C, Dodd LG, DeLong DM, Beam CA, Vaslef S: Making the diagnosis of acute appendicitis: do more preoperative CT scans mean fewer negative appendectomies? A 10-year study. Radiology 2010, 254:460-8.

7. RODNEY DSR: Clinical study of appendicitis in paediatric age Group. RAJIV GANDHI UNIVERSITY OF HEALTH SCIENCES, 2014.

8. Lee SL, Walsh AJ, Ho HS: Computed tomography and ultrasonography do not improve and may delay the diagnosis and treatment of acute appendicitis. Archives of surgery 2001, 136:556-

62.

9. Humes D, Simpson J: Acute appendicitis. Bmj 2006, 333:530-4.

10. Rothrock SG, Pagane J: Acute appendicitis in children: emergency department diagnosis and management. Annals of emergency medicine 2000, 36:39-51.

11. Tanksley S, Young N, Paterson A, Bonierbale M: RFLP mapping in plant breeding: new tools for an old science. Bio/technology 1989 , 7:257.

12. Blackmore CC, Chang TA, Avey GD: Imaging in acute abdominal pain. Evidence-Based Imaging: Springer, 2006. pp. 457-74.

Copyright: (C) the author(s), 2019. It is an open-access article distributed under the terms of the Creative Commons Attribution License (CC BY 4.0), which permits authors to retain ownership of the copyright for their content, and allow anyone to download, reuse, reprint, modify, distribute and/or copy the content as long as the original authors and source are cited.

How to cite this article: Gouri R, Galani P. Clinical Study of Appendicitis and Complication in Treatment in Paediatric Patients.Acad. J Surg. 2019;2(2):27-29.

DOI: dx.doi.org/10.21276/ajs.2019.2.2.7

Source of Support: Nil, Conflict of Interest: None declared. 